This item was submitted to Loughborough's Research Repository by the author.

Items in Figshare are protected by copyright, with all rights reserved, unless otherwise indicated.

\title{
Low SAR ferrite handset antenna design
}

PLEASE CITE THE PUBLISHED VERSION

PUBLISHER

(C) Institute of Electrical and Electronics Engineers (IEEE)

LICENCE

CC BY-NC-ND 4.0

REPOSITORY RECORD

Kitra, Maria I., C.J. Panagamuwa, Patrick McEvoy, J.C. Vardaxoglou, and J.R. James. 2019. "Low SAR Ferrite Handset Antenna Design". figshare. https://hdl.handle.net/2134/2949. 
This item was submitted to Loughborough's Institutional Repository by the author and is made available under the following Creative Commons Licence conditions.

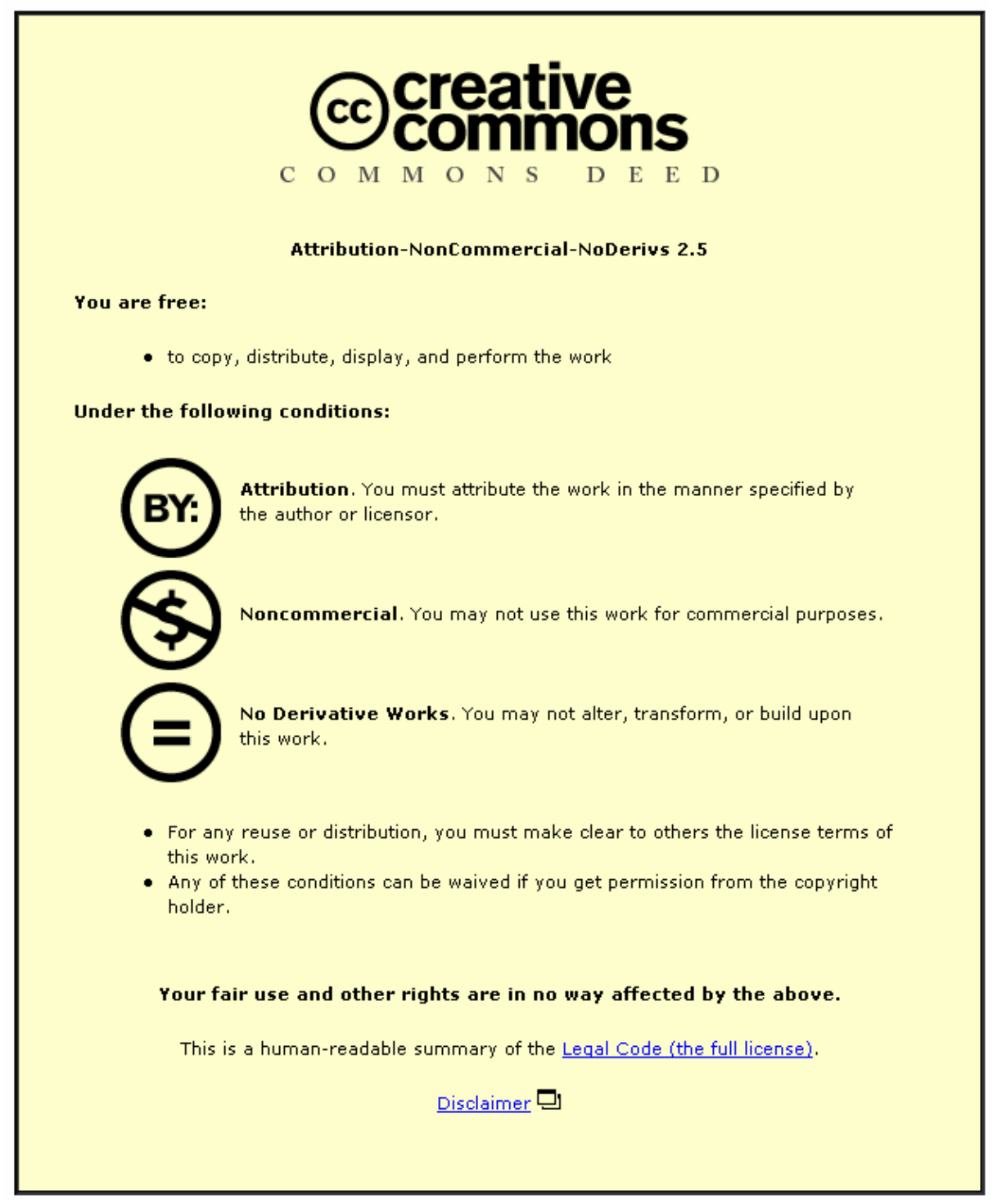

For the full text of this licence, please go to: http://creativecommons.org/licenses/by-nc-nd/2.5/ 


\title{
Low SAR Ferrite Handset Antenna Design
}

\author{
Maria I. Kitra, Member, IEEE, Chinthana J. Panagamuwa, Patrick McEvoy, Member, IEEE, \\ J. (Yiannis) C. Vardaxoglou, Member, IEEE, and Jim R. James
}

\begin{abstract}
The benefits resulting from the inclusion of ferrite in material loaded antennas are investigated, initially through the use of a spherical analytic model and then through a transmission line matrix simulation tool applied to a rectangular slab geometry. It is observed that a material with equality of relative permittivity and permeability in combination with specific positioning of the antenna in relation to the head, can result in the definitive smallsize, high efficiency and bandwidth, low specific absorption rate (SAR) antenna. The accuracy of the simulations is validated both through efficiency and SAR measurements of three material coated monopole samples. Further research into optimizing the above attributes and translating them into a handset antenna leads to a multiband antenna design covering the GSM 1800, 1900, UMTS and Bluetooth bands, with a SAR value reduced by $88 \%$ compared to conventional phones and an efficiency of $38 \%$ at $1.8 \mathrm{GHz}$. A tri-band antenna design is also presented, utilizing currently available lossy ferrite material and it is considered as the first step towards the feasibility of the ultimate low SAR multiband ferrite handset antenna, until further material development specifically for antenna applications takes place.
\end{abstract}

Index Terms-Ferrite loaded antennas, multiband, specific absorption rate (SAR), wireless handset.

It is with sadness we report Prof. James (73) passed away on July 24, 2006, following an illness. He was a force to be reckoned with, he was world renowned for his academic work and had great respect for and from the scientific establishment.

He will remain an important figure in his scientific field of work for years to come, a fine scientist of the old school who will be very sadly missed by colleagues and not least of all by his family. Devoted husband, family man, father, and grandfather, Prof. James was an immense contributor to the engineering community and a highly valued colleague at

Loughborough University. He will be greatly missed.

\section{INTRODUCTION}

$\mathbf{T}$ HE use of material loading to reduce the electrical size of wire monopoles and other antennas is well known [1], [2] and was previously regarded as a technique reserved for a few specialized applications. The antenna size constraints imposed

Manuscript received August 3, 2005; revised May 28, 2006. This work was supported by the U.K. EPSRC under Grant GR/R94596/01.

M. I. Kitra, C. J. Panagamuwa, P. McEvoy, and J. C. Vardaxoglou are with Loughborough University, Loughborough, Leicestershire, LE11 3TU, U.K. (e-mail: m.kitra@lboro.ac.uk; j.c.vardaxoglou@lboro.ac.uk).

J. R. James (deceased) was with Loughborough University, Loughborough, Leicestershire, LE11 3TU, U.K. on leave from Cranfield University, RMCS, Shrivenham, Swindon, Wilts., SN6 8LA, U.K.

Color versions of one or more of the figures in this paper are available online at http://ieeexplore.ieee.org.

Digital Object Identifier 10.1109/TAP.2007.893370 by mobile handset requirements and the availability of new dielectric materials has created much interest in dielectric loaded antennas [3], [4]. Tuning stability and good isolation from the handset and the human operator are cited as important features of dielectric loading which may enable a stand-alone ceramic chip antenna to be finally realized in practice over all the operating bands. There is also some expectation that somewhat less power is dissipated in the operator's head but the orientation of the dielectric antenna with respect to the head and the position of the antenna inside the handset in relation to the electronics is likely to remain the major influence on the specific absorption rate (SAR).

The use of ferrite material loading has previously been investigated [5], [6] but it is only recently that the merits of equalizing the material relative permittivity and permeability values have been reported [7]-[9]. The benefits include increased bandwidth (BW) and radiation efficiency $(\eta)$. The influence of magnetic material on dielectric resonator antennas has also been investigated [10]. A previous study [11] used a very lossy ferrite sheet attachment on the handset case to reduce SAR. Realizing ferrite material as a metamaterial has been considered [12]. However for handset compacted antenna applications the metamaterial heterogeneity and obtaining a small enough cell size are apparent difficulties with this concept.

In this present research the above-established material loading techniques were brought together to create a multiband low SAR handset antenna. The continued reduction in the SAR is of interest to both manufacturers and users and is the central theme in this present research. The present paper commences with the analysis of generic spherical shaped loaded monopoles and their extension to more realistic shapes. Optimal bandwidth, radiation efficiency and SAR properties are demonstrated by simulation using Flomerics' microstripes transmission line matrix (TLM) method and measurements. In particular, the influence of the choice of materials and the antenna excitation process on the near-fields and hence SAR, are considered. Retention of the antenna performance when embedded in a typical handset ground plane has received much attention in the present research and simulated results are included making available many design options to achieve the multiband low SAR operation. These are described in detail and final design recommendations are presented.

\section{Fundamental Design AsPects}

\section{A. Generic Spherical Model}

The antenna performance advantages of using a ferrite loading material are shown analytically by the following spherical model with infinitesimally small Hertzian excitation 
sources. The spherical volume of material has the following relative permeability, relative permittivity and loss tangents:

$$
\begin{aligned}
& \mu_{\mathrm{r}}=\mu^{\prime}+\mathrm{j} \mu^{\prime \prime} ; \quad \tan \delta_{\mu}=\mu^{\prime \prime} / \mu^{\prime} \\
& \varepsilon_{\mathrm{r}}=\varepsilon^{\prime}+\mathrm{j} \varepsilon^{\prime \prime} ; \quad \tan \delta_{\varepsilon}=\varepsilon^{\prime \prime} / \varepsilon^{\prime} .
\end{aligned}
$$

The sphere of radius a is excited at the origin $\mathrm{O}$ by either a magnetic (TE) or an electric (TM) multipole source having $\exp [-\mathrm{j} \omega \mathrm{t}]$ time dependence. The fields are expressed as $\exp [\mathrm{jm} \phi] \mathrm{P}_{\mathrm{n}}^{\mathrm{m}}(\cos \theta) \mathrm{R}(\mathrm{r})$, where $\mathrm{n}=1,2,3 \ldots \infty$, $\mathrm{m}=0,1,2,3 \ldots \mathrm{n},(\mathrm{r}, \theta, \varphi)$ are spherical coordinates, $\mathrm{P}_{\mathrm{n}}^{\mathrm{m}}(\cos \theta)$ are Associated Legendre functions and $\mathrm{R}(\mathrm{r})$ is either a spherical Bessel function of the first kind $j_{n}(r)$ or of the third kind $h_{n}^{(1)}(r)$. On invoking continuity of the tangential fields at $\mathrm{r}=\mathrm{a}$ for each $(\mathrm{nm})$ th eigenfunction, the fields for $\mathrm{r} \geq \mathrm{a}$ have an amplitude governed by

$$
\frac{\mathrm{A}_{\mathrm{nm}}\left[\left[\rho_{1} \mathrm{~h}_{\mathrm{n}}^{(1)}\left(\rho_{1}\right)\right]^{\prime} \mathrm{j}_{\mathrm{n}}\left(\rho_{1}\right)-\left[\rho_{1} \mathrm{j}_{\mathrm{n}}\left(\rho_{1}\right)\right]^{\prime} \mathrm{h}_{\mathrm{n}}^{(1)}\left(\rho_{1}\right)\right]}{\mathrm{K}\left[\rho_{2} \mathrm{~h}_{\mathrm{n}}^{(1)}\left(\rho_{2}\right)\right]^{\prime} \mathrm{j}_{\mathrm{n}}\left(\rho_{1}\right)-\left[\rho_{1} \mathrm{j}_{\mathrm{n}}\left(\rho_{1}\right)\right]^{\prime} \mathrm{h}_{\mathrm{n}}^{(1)}\left(\rho_{2}\right)}
$$

where $[\mathrm{f}(\rho)]^{\prime}$ denotes differentiation of $\mathrm{f}(\rho)$ with respect to $\rho$, $\mathrm{A}_{\mathrm{nm}}$ is the (nm)th source amplitude, $\rho_{1}=\mathrm{k}_{1} \mathrm{a}, \rho_{2}=\mathrm{k}_{2} \mathrm{a}$, $\mathrm{k}_{1}=\mathrm{k}_{0}\left(\mu_{\mathrm{r}} \varepsilon_{\mathrm{r}}\right)^{1 / 2}, \mathrm{k}_{2}=2 \pi / \lambda_{0}, \lambda_{0}=$ freespace wavelength and

$$
\begin{aligned}
\mathrm{K}= & \mu_{\mathrm{r}} \text { for } \mathrm{TE}(\text { transverse electric }) \\
& \text { magnetic sources } \\
= & \varepsilon_{\mathrm{r}} \text { for TM (transverse magnetic) } \\
& \text { electric sources } \\
\left(\mu_{\mathrm{r}} \varepsilon_{\mathrm{r}}\right)^{1 / 2}= & \left(\mu^{\prime} \varepsilon^{\prime} / 2\right)^{1 / 2}\left\{\left(\mathrm{t}_{1}+\mathrm{t}_{2}\right)^{1 / 2}+\mathrm{j}\left(-\mathrm{t}_{1}+\mathrm{t}_{2}\right)^{1 / 2}\right\} \\
\mathrm{t}_{1}= & 1-\tan \delta_{\mu} \tan \delta_{\varepsilon} \\
\mathrm{t}_{2}= & \left(1+\tan \delta_{\mu}^{2} \tan \delta_{\varepsilon}^{2}+\tan \delta_{\mu}^{2}+\tan \delta_{\varepsilon}^{2}\right)^{1 / 2}
\end{aligned}
$$

When the sphere is electrically small the low order $\mathrm{TE}_{\mathrm{nm} \nu}$ and $\mathrm{TM}_{\mathrm{nm} \nu}$ resonator modes are narrow band and the dielectric resonator antenna (DRA) fields can be represented by the $(\mathrm{nm} \nu)^{\text {th }}$ mode alone where $\nu$ relates to the sphere electrical size. In this present paper we are interested in the dipole-like far-fields of the $\mathrm{TE}_{101}$ and $\mathrm{TM}_{101}$ modes corresponding to magnetic and electric dipole excitation sources respectively, as realized in practice by a small wire loop or dipole wire probe. In the presence of a conductive ground plane the $\mathrm{TM}_{101}$ mode is excited by a monopole probe but the $\mathrm{TE}_{101}$ mode is not compatible with the ground plane boundary conditions. A small slot in the ground plane will however excite the $\mathrm{TE}_{111}$ mode which is the $\mathrm{TE}_{101}$ mode with a $90^{\circ}$ rotation of axis.

The complex roots of the denominator of (2) for the $\mathrm{TE}_{101}$ and $\mathrm{TM}_{101}$ modes are respectively $\mathrm{p}_{\mathrm{M}}=\mathrm{p}_{\mathrm{M}}^{\prime}+\mathrm{j} \mathrm{p}_{\mathrm{M}}^{\prime \prime}$ and $\mathrm{p}_{\mathrm{E}}=$ $\mathrm{p}_{\mathrm{E}}^{\prime}+\mathrm{j} \mathrm{p}_{\mathrm{E}}^{\prime \prime}$. The antenna $\mathrm{Q}$ factors are then given by

$$
\mathrm{Q}_{\mathrm{M}}=\mathrm{p}_{\mathrm{M}}^{\prime} /\left(2 \mathrm{p}_{\mathrm{M}}^{\prime \prime}\right), \quad \mathrm{Q}_{\mathrm{E}}=\mathrm{p}_{\mathrm{E}}^{\prime} /\left(2 \mathrm{p}_{\mathrm{E}}^{\prime \prime}\right)
$$

and relate to the energy lost to radiation. The reciprocal of $\mathrm{Q}$ is a useful measure [10] of the antenna impedance bandwidth when a finite size loop or probe is the excitation source. Losses in the

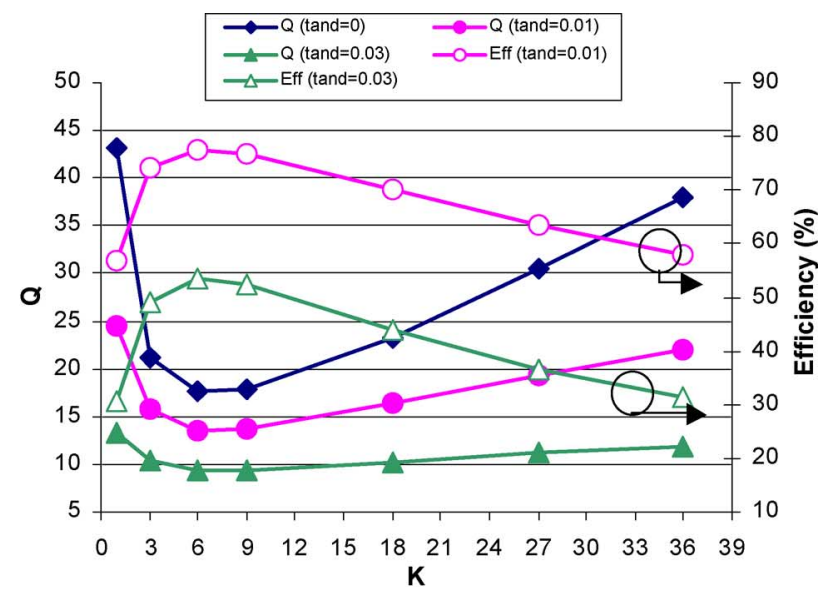

(a)

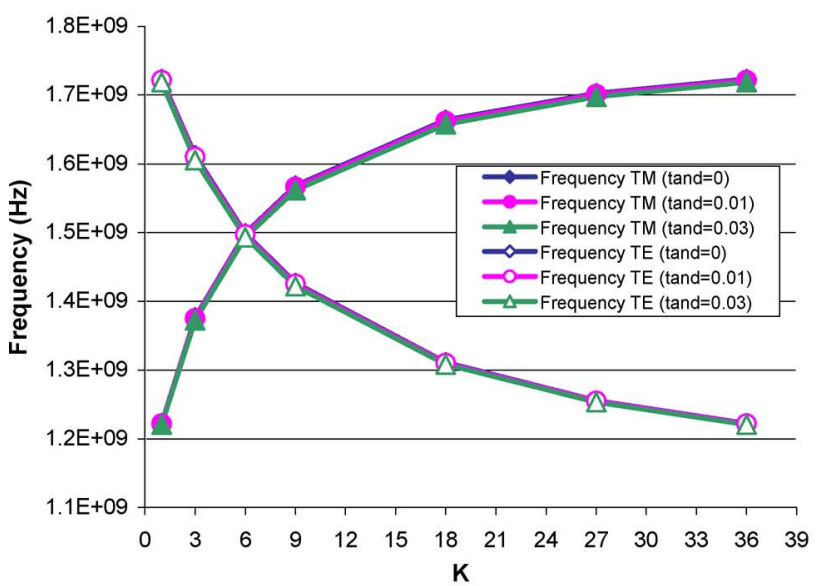

(b)

Fig. 1. Theoretical radiation performance of spherical material coated antenna, radius $20 \mathrm{~mm}$, with central Hertzian electric or magnetic dipole excitation showing variation with $\mathrm{K}$ and losses; $\tan \delta_{\varepsilon}=\tan \delta_{\mu}=$ tand. (a) $\mathrm{Q}$ factor and efficiency $\eta$ and (b) resonant frequency $\mathrm{f}_{\mathrm{o}}^{\mathrm{M}}$ and $\mathrm{f}_{\mathrm{o}}^{\mathrm{E}}$.

material, lower the $\mathrm{Q}$ values to $\mathrm{Q}_{\mathrm{M}}^{\mathrm{L}}$ and $\mathrm{Q}_{\mathrm{E}}^{\mathrm{L}}$ and the antenna radiation efficiencies $\eta_{\mathrm{M}}$ and $\eta_{\mathrm{E}}$ are respectively given by

$$
\eta_{\mathrm{M}}=\left(\mathrm{Q}_{\mathrm{M}}^{\mathrm{L}} / \mathrm{Q}_{\mathrm{M}}\right) \times 100 \%, \quad \eta_{\mathrm{E}}=\left(\mathrm{Q}_{\mathrm{E}}^{\mathrm{L}} / \mathrm{Q}_{\mathrm{E}}\right) \times 100 \% \text {. }
$$

The antenna resonant frequencies $\mathrm{f}_{\mathrm{O}}^{\mathrm{M}}$ and $\mathrm{f}_{\mathrm{O}}^{\mathrm{E}}$ are derived from the real part of the complex roots as

$$
\begin{aligned}
\mathrm{f}_{\mathrm{o}}^{\mathrm{M}}(\mathrm{Hz}) & =\mathrm{p}_{\mathrm{M}}^{\prime} \times 3 \times 10^{8} / \mathrm{a}(\mathrm{cm}) \times 10^{-2} \times 2 \pi \\
\mathrm{f}_{\mathrm{o}}^{\mathrm{E}}(\mathrm{Hz}) & =\mathrm{p}_{\mathrm{E}}^{\prime} \times 3 \times 10^{8} / \mathrm{a}(\mathrm{cm}) \times 10^{-2} \times 2 \pi .
\end{aligned}
$$

Examination of (1)to (6) indicates that for moderate material losses the radiation is enhanced when $\mu^{\prime}$ is of comparable value to $\varepsilon^{\prime}$. This important property is illustrated in Fig. 1(a) for both the $\mathrm{TM}_{101}$ and $\mathrm{TE}_{101}$ modes, with $a=20 \mathrm{~mm}$ and constant $\mu^{\prime} \varepsilon^{\prime}$ product of 36. According to the definition of K in (3), Fig. 1 represent either the $\mathrm{TM}_{101}$ mode when $\mathrm{K}=\varepsilon_{\mathrm{r}}$ or the $\mathrm{TE}_{101}$ when $\mathrm{K}=\mu_{\mathrm{r}}$, corresponding to Hertzian electric and magnetic dipole excitation sources respectively. Note that the small losses allow $\mathrm{K}$ to be taken as $\varepsilon^{\prime}$ or $\mu^{\prime}$ for ease of presentation. For both modes, the minimum $\mathrm{Q}$ and hence maximum $\mathrm{BW}$ occurs when $\mu^{\prime}=\varepsilon^{\prime}=6$; this holds over a wide range of material loss values. In the lossless case both modes have the same $\mathrm{Q}$ values. 
It should be noted that (3) has symmetry in $\tan \delta_{\mu}$ and $\tan \delta_{\varepsilon}$ so each loss affects the antenna performance to the same extent.

The ratio $\mu^{\prime} / \varepsilon^{\prime}$ has an influence on the resonant frequency but the latter is relatively insensitive to the level of material loss as shown in Fig. 1(b).

A similar resonant frequency insensitivity is observed when the sphere is immersed in a lossy media thus supporting the claims, noted above, that material loaded antennas are less affected by their environment. Fig. 1(a) gives the $\eta$ and Q plots, showing that maximum radiation is released when $\mu^{\prime}=\varepsilon^{\prime}=6$. From a physical standpoint it would seem for the spherical geometry at least, that equality of $\mu^{\prime}$ and $\varepsilon^{\prime}$ provides the best impedance match at the air/material interface. The greatest electrical size reduction however does not correspond to the latter condition and from the resonant frequency plot in Fig. 1(b) is seen to occur for the $\mathrm{TM}_{101}$ mode, when $\mathrm{K}=\varepsilon^{\prime}=1$ and $\mu^{\prime}=36$; for this condition the spherical surface is approximately an electric wall and the nature of the antenna external near field is predominantly electric [13]. The boundary conditions on the sphere are thus compatible with the electric excitation source [10]. Conversely for the $\mathrm{TE}_{101}$ mode, minimum electrical size occurs when $\mathrm{K}=\mu^{\prime}=1$ and $\varepsilon^{\prime}=36$; for this condition the spherical surface is approximately a magnetic wall, the nature of the external antenna near field is predominantly magnetic [13] and the boundary conditions on the sphere are thus compatible with the magnetic excitation source [10]. The boundary conditions are incompatible for other combinations of excitation sources and material composition and no clear distinction can be made regarding the nature of the antenna near fields.

Another interesting property is that the resonant frequencies of the $\mathrm{TM}_{101}$ and $\mathrm{TE}_{101}$ modes [Fig. 1(b)] converge to the same frequency at $\mu^{\prime}=\varepsilon^{\prime}=6$. This could be of practical use in the design of circularly polarized material loaded antennas [14], given the appropriate combined electric and magnetic dipole excitation with quadrature phase. From the examination of a few higher modes it would appear that the above properties hold for all higher modes in this spherical geometry.

\section{B. Rectangular Block-Shaped Antenna}

Practical loaded dipole antennas are very likely to depart from spherical geometry and also the dipole excitation may be offset from the origin $O$, usually to adjust the input impedance match to the antenna. The effect of offsetting the excitation in a spherical shaped loaded antenna is to excite both TE and TM modes, as may be deduced from translation addition theorems for spherical vector wavefunctions [15]. In practice the effect is to detune and generate cross-polarization; an example for a hemispherical loaded monopole probe has previously been given [10]. Likewise any departure of the material surface from spherical shape and/or the inclusion of finite size excitation sources will detune and generate cross-polarized fields, depending on the extent to which the spherical surface is deformed and/or source size.

Cylindrical and rectangular surfaces are likely shapes and an example of the latter is shown in Fig. 2 for a wire dipole TM excitation; $\mu^{\prime} \varepsilon^{\prime}=36$ and the antenna dimensions are $40 \times 40 \times$ $40 \mathrm{~mm}$ (width $\times$ length $\times$ height).

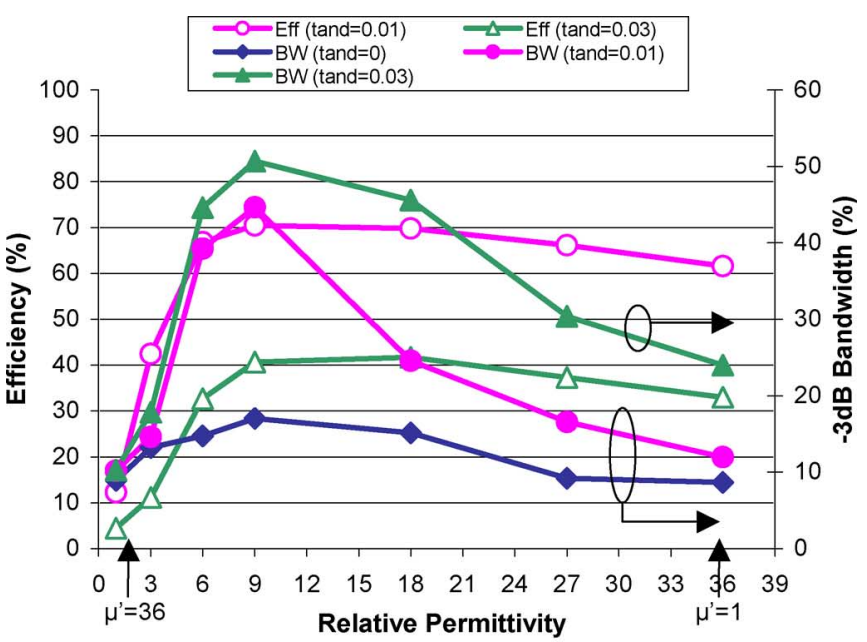

(a)

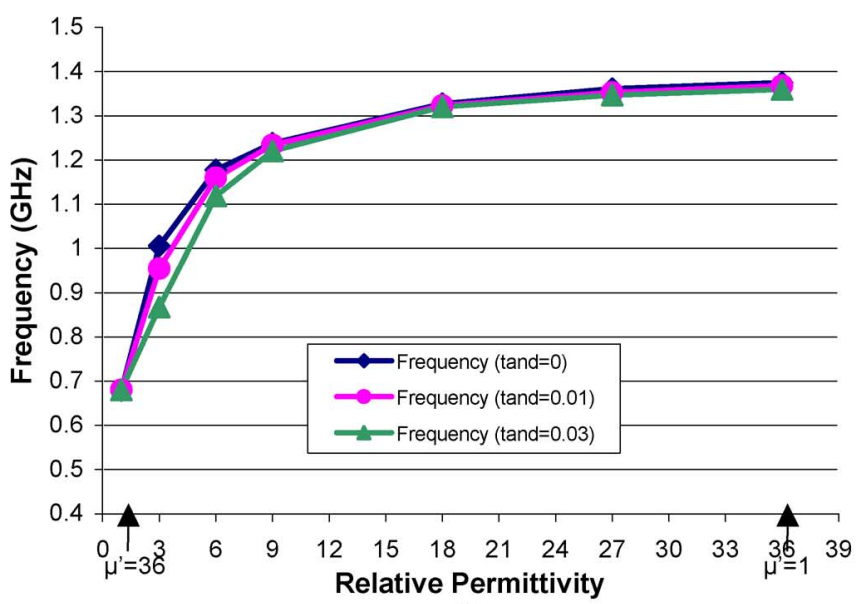

(b)

Fig. 2. Simulated radiation performance of $40 \times 40 \times 40 \mathrm{~mm}$ rectangular material coated antenna with central dipole excitation showing variation with relative permittivity; dip ole radius $=0.5 \mathrm{~mm} ; \tan \delta_{\varepsilon}=\tan \delta_{\mu}=$ tand. (a) Efficiency $\eta$ and bandwidth BW (b) resonant frequency.

Good matching at $1800 \mathrm{MHz}$ was achieved in the simulation by adjusting the dipole length which varied between 29.5 and $13.5 \mathrm{~mm}$. When $\mu^{\prime}$ and $\varepsilon^{\prime}$ are of similar value the antenna has maximum BW and $\eta$ Fig. 2(a) over a range of material losses. The variation of resonant frequency (TM) with $\varepsilon^{\prime}$ indicates maximum electrical size reduction when $\varepsilon^{\prime}=1$ and $\mu^{\prime}=36$ as shown in Fig. 2(b). The material volume exceeds that of the spherical antenna in Fig. 1 and accounts for the lowering of the resonant frequencies. This resonant action is denoted by $\mathrm{TM}_{101}^{\prime}$ since its behavior relates to that of the $\mathrm{TM}_{101}$ spherical mode.

For actual design purposes in the sections that follow it is required to optimize the antenna at a particular frequency. For this purpose the antenna match is again optimized by varying the excitation dipole (or monopole) length but the resonant frequency is held constant at $1800 \mathrm{MHz}$, thus allowing the $\mu^{\prime} \varepsilon^{\prime}$ product to vary.

\section{Radiation Efficiency Measurements}

In this present paper, attention is focused on the rectangular block $\mathrm{TM}_{101}^{\prime}$ mode with monopole excitation because it proved 
TABLE I

MeAsured AND Simulated RESONANT FREQUENCY $\mathrm{f}^{\mathrm{E}^{\prime}}, \mathrm{S}_{11}$ AND $\eta$ OF FERRITE ANTENNA SAMPLES IN THE TM ${ }_{101}^{\prime}$ MODE

\begin{tabular}{|c|c|c|c|c|c|c|}
\hline \multirow{2}{*}{$\begin{array}{c}\text { Sample } \\
\text { No. }\end{array}$} & \multicolumn{3}{|c|}{ measured } & \multicolumn{3}{c|}{ simulated } \\
\cline { 2 - 7 } & $\begin{array}{c}\mathrm{f}_{\mathrm{o}}^{\mathrm{E}^{\prime}} \\
(\mathrm{GHz})\end{array}$ & $\begin{array}{c}\mathrm{S}_{11} \\
(\mathrm{~dB})\end{array}$ & $\begin{array}{c}\eta \\
(\%)\end{array}$ & $\begin{array}{c}\mathrm{f}_{\mathrm{o}}^{\mathrm{E}^{\prime}} \\
(\mathrm{GHz})\end{array}$ & $\begin{array}{c}\mathrm{S}_{11} \\
(\mathrm{~dB})\end{array}$ & $\begin{array}{c}\eta \\
(\%)\end{array}$ \\
\hline 1 & 1.83 & -14.13 & 15 & 1.78 & -12.0 & 17 \\
2 & 2.45 & -18.0 & 63 & 2.41 & -12.0 & 66.5 \\
3 & 2.43 & -10.6 & 83 & 2.42 & -13.4 & 78 \\
\hline
\end{tabular}

to be most appropriate for the handset installation. Three samples of hexagonal ferrite material were cut to size and drilled to accommodate the $0.5 \mathrm{~mm}$ radius monopole excitation probe that was back-fed on a $250 \times 250 \mathrm{~mm}$ ground plane. The radiation efficiency $\eta$ of the $\mathrm{TM}_{101}^{\prime}$ mode was then measured using the Wheeler cap method [16], [17]. The cap diameter was $73 \mathrm{~mm}$, which satisfied the radian sphere limitation. Sample 1 had dimensions $50 \times 50 \times 18 \mathrm{~mm}$ and a monopole of length $15 \mathrm{~mm}$. The following properties were assessed from measurements: $\varepsilon^{\prime} \sim 5.5, \mu^{\prime} \sim 1.5, \tan \delta_{\varepsilon} \sim 0.03$ and $\tan \delta_{\mu} \sim 0.14$ indicating a high magnetic loss, as confirmed by the measured and simulated data in Table I. For this sample $\eta$ was also checked using a transmission system test.

Sample 2 had dimensions $25 \times 2 \times 27 \mathrm{~mm}$ cut from MF112 material manufactured by Emerson and Cuming with quoted properties: $\varepsilon^{\prime} \sim 5.2, \mu^{\prime} \sim 1.5, \tan \delta_{\varepsilon} \sim 0.05$ and $\tan \delta_{\mu} \sim$ 0.03 . Although intended for screening purposes, this material was far less lossy than that in sample 1 and gave a reasonably high $\eta$ as seen in Table I, using a $12 \mathrm{~mm}$ monopole; a $-10 \mathrm{~dB}$ $\mathrm{BW}$ of $44 \%$ was measured at $2.45 \mathrm{GHz}$.

A 2-mm thick flexible sheet of material intended for use as a white-board marker, was found to possess magnetic properties at the lower microwave frequencies. The material was cut into square pieces and stacked to provide sample 3 with dimensions $20 \times 20 \times 30 \mathrm{~mm}$. The antenna resonated at $2.43 \mathrm{GHz}$ with a $12 \mathrm{~mm}$ monopole probe. The assessed material properties were: $\varepsilon^{\prime} \sim 4.3, \mu^{\prime} \sim 1.4, \tan \delta_{\varepsilon} \sim 0.03$ and $\tan \delta_{\mu} \sim 0.02$ resulting in a less compact but higher efficiency antenna, as shown in Table I. It is concluded that the simulations and measurements are in good agreement considering that the latter have tolerances of the order $\pm 5 \%$.

\section{Low SAR Antenna Design}

The SAR was simulated using a homogeneous spherical phantom of radius $75 \mathrm{~mm}$. It has been established [18]-[21] that the use of a homogeneous spherical phantom gives worse-case simulation of the peak $10 \mathrm{~g}$ SAR compared to an anatomically accurate heterogeneous phantom head. Computations times are also much less for the former.

The phantom material parameters chosen were $\varepsilon_{r}=41$, conductivity $\sigma=1.65 \mathrm{~S} / \mathrm{m}$ and density $\rho=1030 \mathrm{~kg} / \mathrm{m}^{3}$ which resemble human tissue. The antenna radiating power external to the antenna was normalized at $125 \mathrm{~mW}$. In all the simulations in this paper the sphere surface was placed $15 \mathrm{~mm}$ dis-

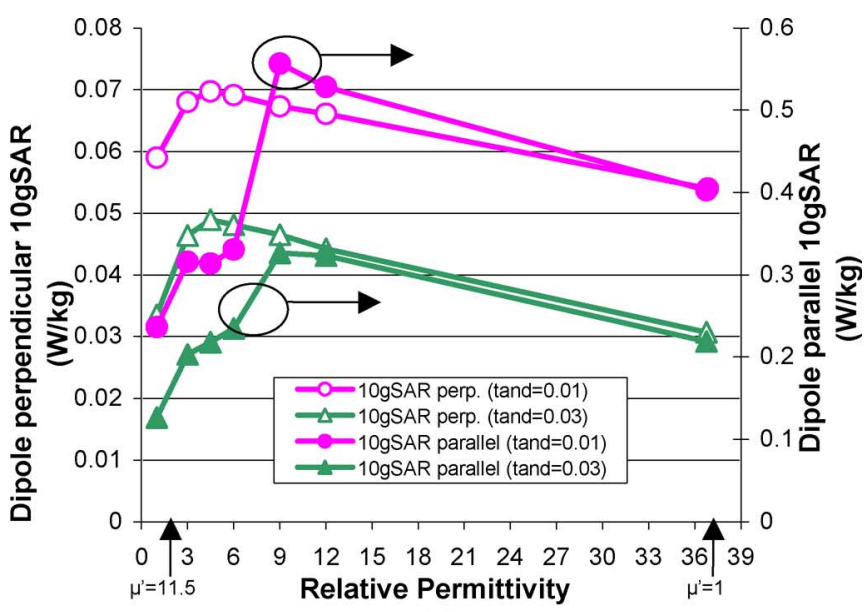

(a)

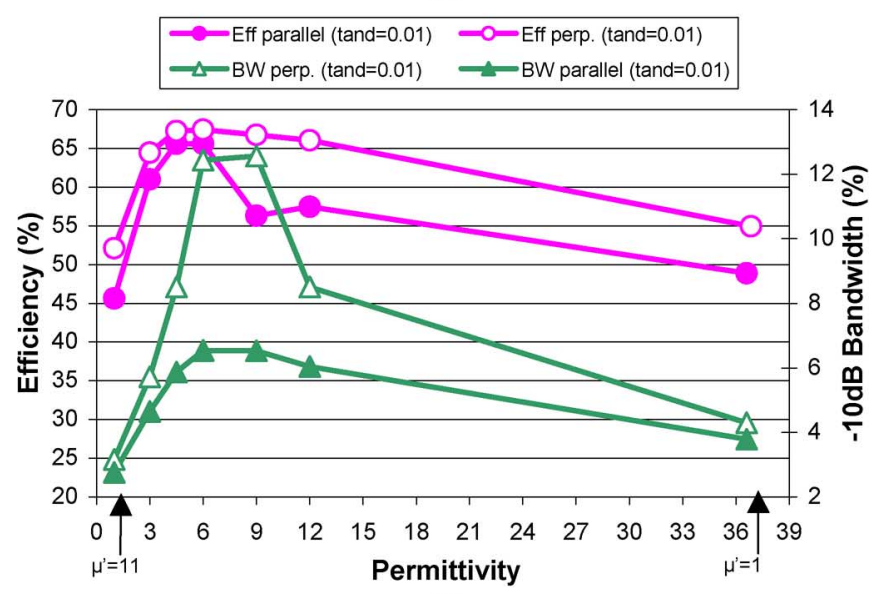

(b)

Fig. 3. Simulated radiation performance of $30 \times 30 \times 30 \mathrm{~mm}$ rectangular material coated antenna with central dipole excitation showing variation with relative permittivity; dipole radius $=0.5 \mathrm{~mm} ; \tan \delta_{\varepsilon}=\tan \delta_{\mu}=\operatorname{tand}$. (a) SAR for perpendicular and parallel dipole orientation and (b) efficiency $\eta$ and bandwidth BW.

tant from the antenna surface of interest. Two antenna orientations with respect to the phantom were investigated: i) the monopole or dipole axis is parallel to the sphere surface and the dipole-like broadside beam is directed at the latter, ii) the monopole or dipole axis is perpendicular to the sphere surface and the dipole-like far-field pattern null is directed at the latter resulting in a significant SAR reduction. This is illustrated in Fig. 3 for a $30 \times 30 \times 30 \mathrm{~mm}$ material cube.

The excitation dipole was varied in height from 9 to $20 \mathrm{~mm}$ to maintain tuning at $1800 \mathrm{MHz}$ while $\mu^{\prime}$ and $\varepsilon^{\prime}$ were also varied; the material losses were constant at $\tan \delta_{\varepsilon, \mu} \sim 0.01$ and 0.03 . Maximum $\eta$, BW and SAR occur in the vicinity of $\mu^{\prime} \sim \varepsilon^{\prime}$ for both orientations but the SAR is greatly reduced and $\eta$, BW are increased for perpendicular orientation. The near-fields in the pattern null contribute relatively more to the SAR, particularly if they are magnetic dominant with the ability to more easily penetrate the human body [18], but Fig. 3(a) and other simulations show little or no distinction between the nature of these near-fields. Sample 1 of Table I was measured in the perpendicular orientation using the SPEAG Dosimetric Assessment System (DASY 4) [23]. This system comprises of an isotropic 


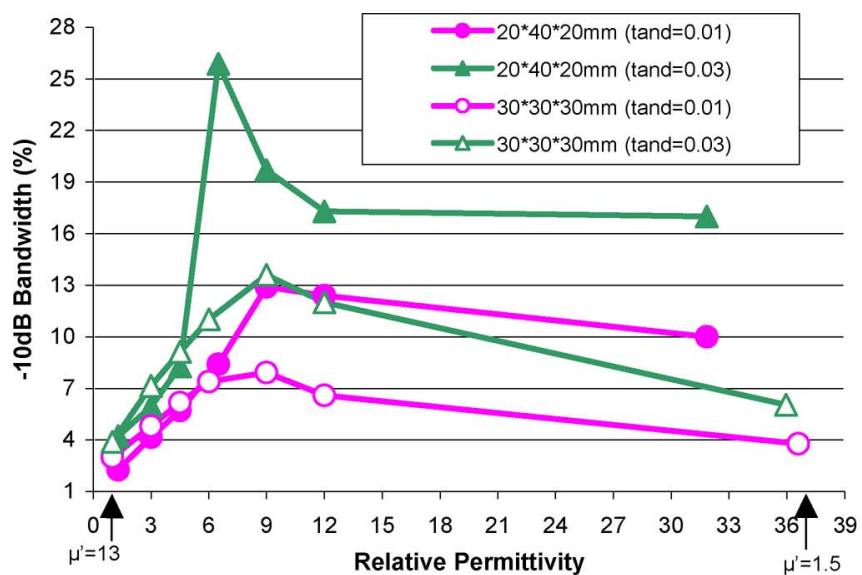

(a)

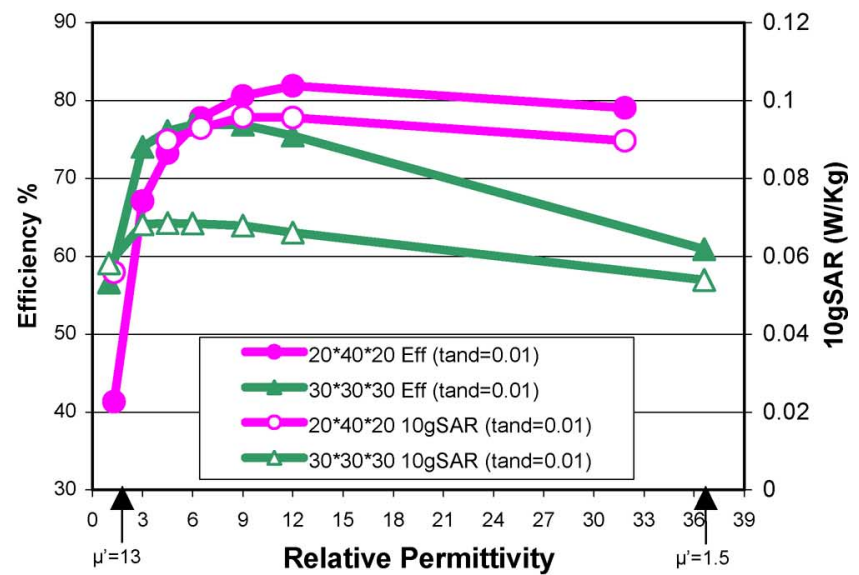

(b)

Fig. 4. Simulated results showing the effect of increasing the height profile of a $30 \times 30 \times 30 \mathrm{~mm}$ rectangular material coated antenna with central dipole excitation to $20 \times 20 \times 40 \mathrm{~mm}$ showing variation with relative permittivity; dipole radius $=0.5 \mathrm{~mm}$; $\tan \delta_{\varepsilon}=\tan \delta_{\mu}=$ tand. (a) bandwidth $\mathrm{BW}$ (b) efficiency $\eta$ and SAR (perpendicular orientation).

E-field probe controlled by a 6-axis robotic arm, scanning the inside of a phantom head with facial features filled with tissue simulating liquid. A measured $10 \mathrm{~g}$ SAR of $0.21 \mathrm{~W} / \mathrm{kg}$ was measured compared to a simulated value of $0.3 \mathrm{~W} / \mathrm{kg}$.

\section{E. Techniques for Increasing Bandwidth}

A higher profile antenna has a reduced separation between the $\mathrm{TM}_{101}^{\prime}$ and $\mathrm{TM}_{102}^{\prime}$ modes and this can usefully increase the $\mathrm{S}_{11}$ bandwidth of the $\mathrm{TM}_{101}^{\prime}$ as illustrated in Fig. 4(a) at $1800 \mathrm{MHz}$.

The antenna was optimized for the widest bandwidth at a $-10 \mathrm{~dB}$ level by adjusting the monopole length. The $-10 \mathrm{~dB}$ bandwidth has increased from a maximum of $7.9 \%$ to $12.9 \%$ for $\tan \delta_{\varepsilon \mu}=0.01$ and from $13.6 \%$ to $25.87 \%$ for $\tan \delta_{\varepsilon \mu}=0.03$. The dimensions of the antennas are: i) low profile block size was $30 \times 30 \times 30 \mathrm{~mm}$, dipole length $=11 \mathrm{~mm}, \varepsilon^{\prime} \sim 9$, $\mu^{\prime} \sim 3.3$, and ii) higher profile block size was $20 \times 20 \times 40 \mathrm{~mm}$, dipole length $=8.5 \mathrm{~mm}, \varepsilon^{\prime} \sim 6.5, \mu^{\prime} \sim 6.4$. In Fig. 4(b) it is seen that the higher profile antenna has a $3.7 \%$ increase in $\eta$ and a $28 \%$ increase in SAR when the dipole source of both antennas is $30 \mathrm{~mm}$ from the surface of the phantom. The perpendicular orientation again ensures a very low SAR value.

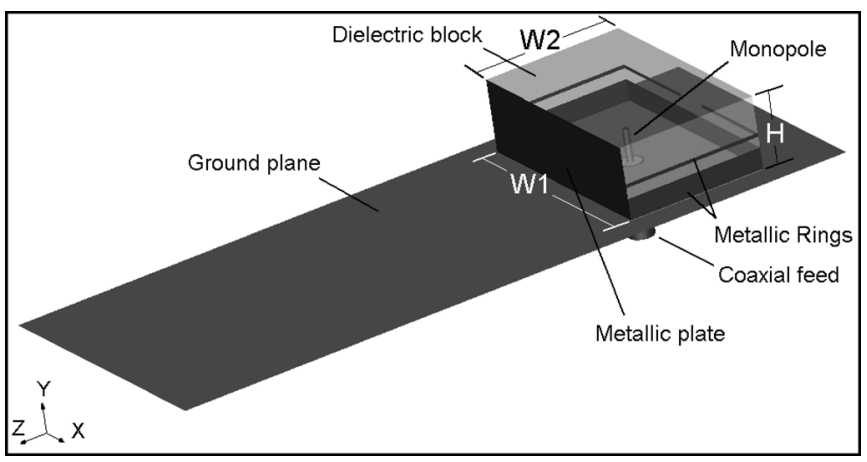

Fig. 5. Layout of simulated handset showing quad-band rectangular material coated antenna with central dipole excitation mounted on $100 \times 40 \mathrm{~mm}$ ground plane.

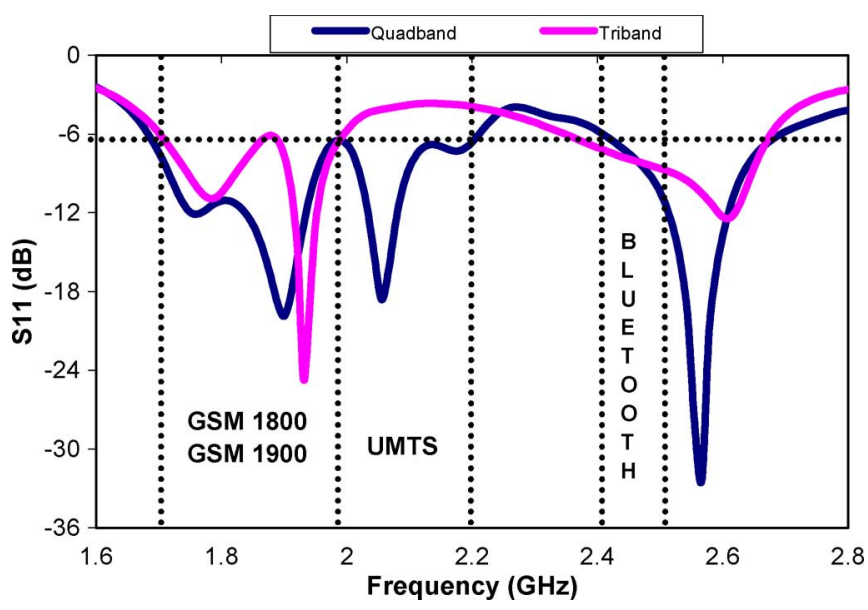

Fig. 6. Simulated $\mathrm{S}_{11}$ characteristic of triband and quadband handset antenna of Fig. 5; $\tan \delta_{\varepsilon}=\tan \delta_{\mu}=0.03$ (triband); $\tan \delta_{\varepsilon} \sim 0, \tan \delta_{\mu}=0.06$ (quadband).

\section{HANDSET ANTENNA DESIGN}

\section{A. Quad Band Antenna Design Objectives}

Integration into the handset involved two initial constraints:

i) the antenna ferrite block had to be mounted on a 40 $\times 100 \mathrm{~mm}$ metal ground plane with a $10 \mathrm{~mm}$ height limitation;

ii) for a low SAR the monopole axis had to be directed perpendicular to the user's head. The latter constraint ruled out deployment of the TE modes whose fields are incompatible with the boundary conditions imposed by the ground plane. The design objective was coverage of the GSM (1710-1880 MHz), GSM (1850-1990 MHz), UMTS (1920-2170 MHz) and Bluetooth (2402-2495 MHz) bands with a single ferrite block. The inclusion of the GSM (900 MHz) band is the subject of ongoing research at present.

\section{B. Developmental Simulation}

A sequence of developmental simulations commenced on a $40 \times 40 \mathrm{~mm}$ ground plane, to investigate the options available for varying the block length to width ratio to optimize $\eta$ and $\mathrm{BW}$ while positioning the $\mathrm{TM}_{101}, \mathrm{TM}_{102}$ mode frequencies to 


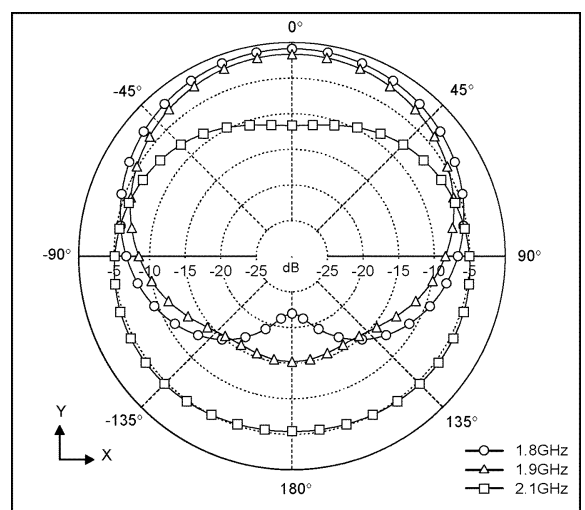

(a)

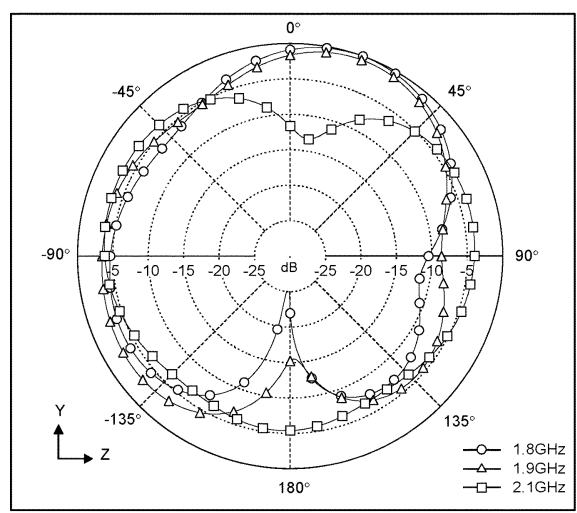

(b)

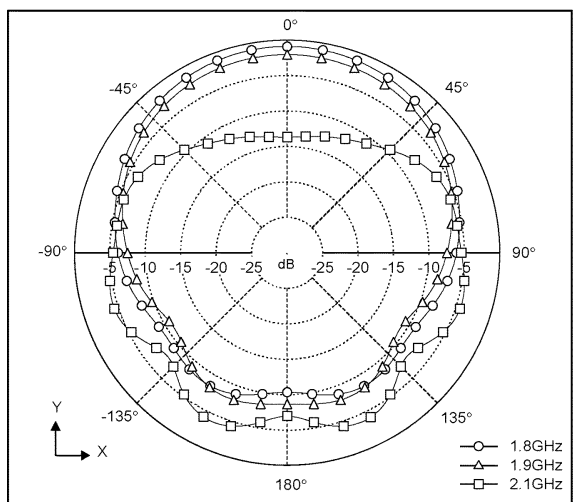

(c)

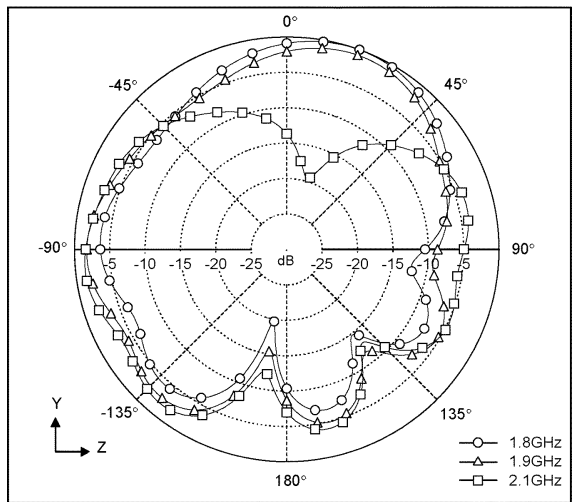

(d)

Fig. 7. Simulated radiation patterns of quad-band antenna shown in Fig. 5. (a) yx plane without head, (b) yz plane without head, (c) yx plane with head, (d) yz plane with head.

1800 and $2450 \mathrm{MHz}$, respectively. The third $1900 \mathrm{MHz}$ band was introduced by the addition of two metal strip rings around
TABLE II

Simulated Design PARAmeters AND PeRformance of QuAd-BAND Rectangular Material CoATED Antenna of Fig. 5 With

CENTRAL MonOPOLE EXCITATION MOUNTED ON A $100 \mathrm{~mm} \times 40 \mathrm{~mm}$ GROUND Plane; $W 1=32 \mathrm{~mm}, \mathrm{~W} 2=20 \mathrm{~mm}, \mathrm{H}=10 \mathrm{~mm}$; monopole radius $=0.45 \mathrm{~mm}$, ring widths $=2.9 \mathrm{~mm}$ FOR LOWER AND $0.5 \mathrm{~mm}$ FOR UPPER, THE FORMER BEING $0.1 \mathrm{~mm}$ ABOVE THE GROUND AND THE LATTER HAVING A CENTRAL 5 mm Tuning GAP

\begin{tabular}{|c|c|c|}
\hline & $\begin{array}{l}\operatorname{tand}_{\varepsilon}=0.03 \\
\operatorname{tand}_{\mu}=0.03\end{array}$ & $\begin{array}{c}\operatorname{tand}_{\varepsilon}=0.0001 \\
\operatorname{tand}_{\mu}=0.06\end{array}$ \\
\hline$\varepsilon^{\prime}$ & 6 & 6.38 \\
\hline$\mu^{\prime}$ & 6.6 & 6.18 \\
\hline Monopole length (mm) & 4.5 & 4.5 \\
\hline $\begin{array}{l}\text { Coverage of GSM } 1800 \text {, } \\
1900, \text { UMTS and } \\
\text { Bluetooth bands at -6dB }\end{array}$ & Achieved & Achieved \\
\hline $\begin{array}{l}\text { Efficiency }(\%) \text { at } 1.8, \\
1.9,2.1 \text { and } 2.45 \mathrm{GHz} \\
\text { respectively }\end{array}$ & $36.8,36.1,19.1,27.5$ & $40.8,39.2,24,27.6$ \\
\hline $\begin{array}{l}\text { SAR } 10 \mathrm{~g}(\mathrm{~W} / \mathrm{kg}) \text { at } \\
1.8 \mathrm{GHz}, 1.9 \mathrm{GHz} \text {, } \\
2.1 \mathrm{GHz} \text { and } 2.45 \mathrm{GHz}\end{array}$ & $\begin{array}{c}0.076,0.11,0.06 \\
0.0006\end{array}$ & $\begin{array}{c}0.077,0.106,0.07 \\
0.0006\end{array}$ \\
\hline $\begin{array}{l}\text { Efficiency }(\%) \text { with } \\
\text { head at } 1.8,1.9,2.1 \text { and } \\
2.45 \mathrm{GHz} \text { respectively }\end{array}$ & $\begin{array}{c}35.05,32.6,15.15 \\
22.34\end{array}$ & $38.5,34.9,19.2,22$ \\
\hline $\begin{array}{l}\text { Efficiency }(\%) \text { with } \\
\text { hand and head at } 1.8, \\
1.9,2.1 \text { and } 2.45 \mathrm{GHz} \\
\text { respectively }\end{array}$ & $\begin{array}{c}23.26,16.8,14.8, \\
13.4\end{array}$ & $25.4,11.7,13.4,13.2$ \\
\hline
\end{tabular}

the block, realizing a tri-band antenna. The ground plane was then extended to $40 \times 100 \mathrm{~mm}$ to comply with typical handset dimensions and by varying $\mu^{\prime}$ and $\varepsilon^{\prime}$, monopole length, position, width and gap of the rings, the fourth UMTS band was achieved, resulting in the realization of a quad-band material loaded antenna. One final constraint was imposed on the simulation: the maintenance of the nulls in the radiation patterns in line with the monopole axis. It was achieved by metallizing the block face overlooking the ground plane, leaving a $0.1 \mathrm{~mm}$ gap at the block base to electrically isolate the metallization and lower ring from the ground plane itself. The finalized design is illustrated in Fig. 5 and the tri-band and quad-band coverage achieved at an $\mathrm{S}_{11}$ level of $-6 \mathrm{~dB}$ are shown in Fig. 6. With no head present, the pattern cuts for the first three quad-bands in Fig. 7(a) and (b) are predominantly dipole-like with well-positioned nulls for the head and hence low SAR operation.

The Bluetooth band pattern cuts resemble those of the UMTS band and give smooth overall coverage. The scattering from the head is far less than that experienced by other types of handset antennas due to the presence of the positioned pattern nulls and the pattern cuts Fig. 7(c) and (d) show less scattering interference in the yx cut than the yz cut.

The quad-band antenna was modelled for two different cases of losses: i) $\tan \delta_{\varepsilon}=\tan \delta_{\mu}=0.03$ and ii) $\tan \delta_{\varepsilon} \sim 0$, $\tan \delta_{\mu}=0.06$, to check the antenna performance against material variation. The results were satisfactory and in both cases the four bands were covered by slight modifications to the $\mu^{\prime}$ and $\varepsilon^{\prime}$ values. The variation of the design parameters with losses as well as a summary of the overall antenna performance is presented in Table II.

Other types of handset antennas such as the PIFA and meander-line antennas [24] typically have radiation efficiencies of $60 \%$ that reduce to $20 \%$ with the head present, in which case 
$10 \mathrm{~g}(\mathrm{~W} / \mathrm{kg}) \mathrm{SAR}$ values between 1 and 2 are encountered have been measured for a head separation distance of $8 \mathrm{~mm}$ [25] and [22, pp. 396-407]. The normalizing input power is not stated in [25]. In contrast, the quad-band handset antenna offers a significant reduction in SAR together with comparable radiation efficiencies in the presence of the head. In addition, the ground plane currents were minimized in the design process by viewing them in the simulation stages and iterating the positions of the various metallized rings and strips. Other ways of minimizing the ground plane currents have been reported [22], [30] with the common aim of creating a stand-alone plug-in antenna component that is less sensitive to its environment. The same head model was also simulated in the presence of a hand, $10 \mathrm{~mm}$ away from the antenna. Compared to other types of antennas [26] whose efficiency drops by $10 \%$ when $15 \mathrm{~mm}$ away from the hand, it was found that the quad-band antenna is less sensitive to the presence of the hand. The radiation efficiency reduces by a maximum of $12 \%$ at $1800 \mathrm{MHz}$ as seen in Table II.

\section{Design Using Existing Materials}

Hexagonal ferrites provide magnetic properties at microwave and millimeter wave frequencies without need for an externally applied magnetic biasing field [27]. Sample 1 of this present paper was a hexagonal ferrite similar to that previously described [28] but was designed for screening applications. The material composition was $\mathrm{Ba} \operatorname{Co} \delta \mathrm{Fe}_{12-2} \delta \mathrm{O}_{19}$, where $\delta$ is the degree of substitution controlling the ferrimagnetic resonant frequency and was set in the range 0.79 to 0.98 . Adjustments to the material composition can optimize the electrical parameters for antenna applications and position the material resonance to correspond to the operating bandwidth. The simulations in this present paper assume that the material parameters are not frequency dependent.

It has been demonstrated that periodically arranged composite dielectric blocks having different permittivities can create an averaging bulk effect [29]. This was seen as a possible way of synthesizing a desired bulk ferrite material effect using slices of material that didn't have the desired electrical parameters but was available. A $30 \times 30 \times 30 \mathrm{~mm}$ rectangular composite material coated antenna with central dipole excitation was comprised of lossless ferrite material (with a relative permittivity of 1.2) in one third of the central volume while the remaining two thirds were filled with lossless dielectric material. Simulations of the configuration were optimized for matched operation at $1800 \mathrm{MHz}$ but the radiation efficiencies and bandwidths were significantly out-performed by the usual homogeneous arrangement as shown in Fig. 8.

Other simulations involving multiple thinner slices were also investigated but consistently gave a lower antenna performance compared to the homogeneous case. The mismatched wave interface between the ferrite and dielectric materials is thought to create additional reflections within the materials accompanied by increased dissipation. It is concluded that a homogeneous material is needed in this present antenna application.

A tri-band antenna design based on a material with $\mu^{\prime}$ properties approximating those of Sample $2\left(\varepsilon^{\prime}=24.1, \mu^{\prime}=2\right.$, $\tan \delta_{\varepsilon}=0.0001, \tan \delta_{\mu}=0.06$, monopole length $=8 \mathrm{~mm}$ ) was simulated and is shown in Fig. 9.

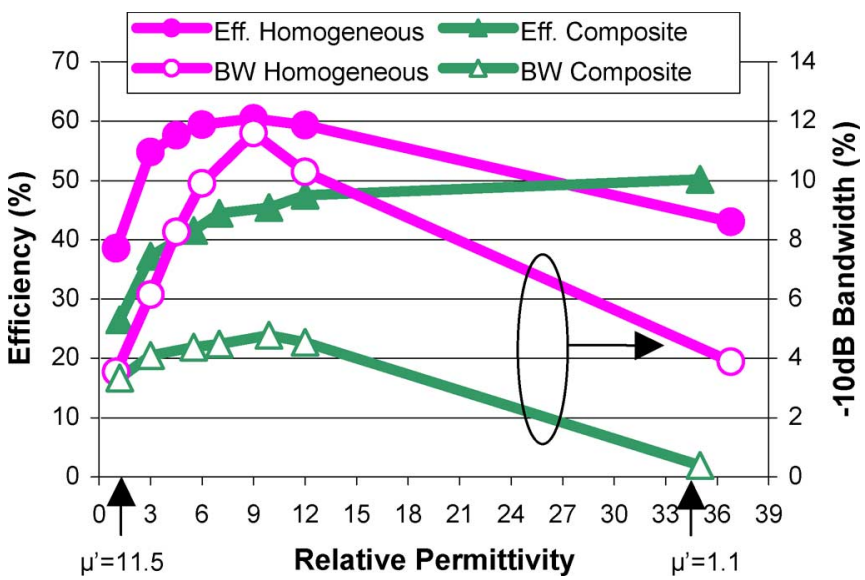

Fig. 8. Simulated efficiency $\eta$ and bandwidth BW of composite $30 \times 30 \times$ $15 \mathrm{~mm}$ rectangular material coated antenna with central dipole excitation compared to homogeneous material antenna, showing variation with relative permittivity.

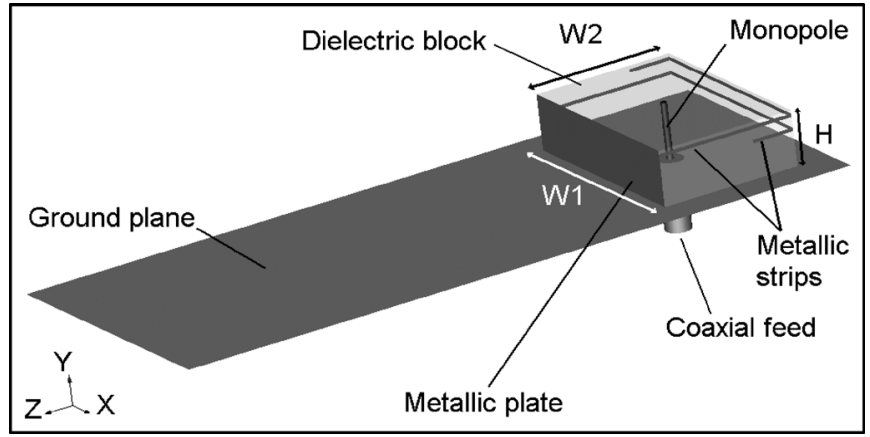

Fig. 9. Layout of simulated handset showing tri-band, reduced $\mu_{\mathrm{r}}$, and rectangular material coated antenna with central dipole excitation mounted on $100 \times 40 \mathrm{~mm}$ ground plane. $(\mathrm{W} 1=30 \mathrm{~mm}, \mathrm{~W} 2=20 \mathrm{~mm}, \mathrm{H}=8 \mathrm{~mm}$; monopole radius $=0.45 \mathrm{~mm}$ and monopole height $=8 \mathrm{~mm}$; ring widths $=0.5 \mathrm{~mm}$, the lower and the upper being 5 and $7 \mathrm{~mm}$, respectively, above the ground, both of them extending $6 \mathrm{~mm}$ along the side walls of the block).

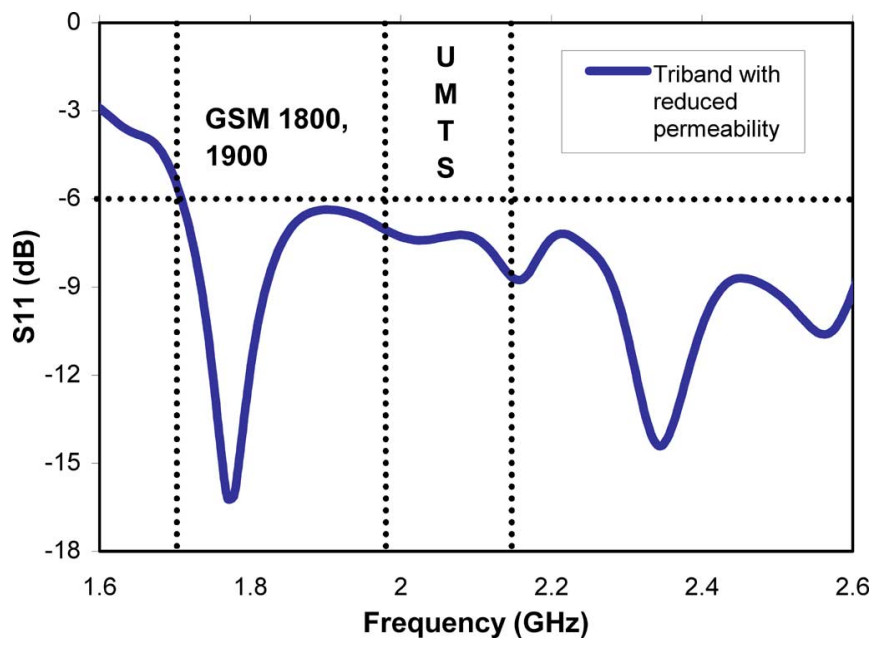

Fig. 10. Simulated S11 characteristic of handset antenna of Fig. 9.

The dimensions of the block have been altered, including a useful reduction in block height $\mathrm{H}$, and the antenna has been redesigned to account for the reduced $\mu^{\prime}$. The bands covered 


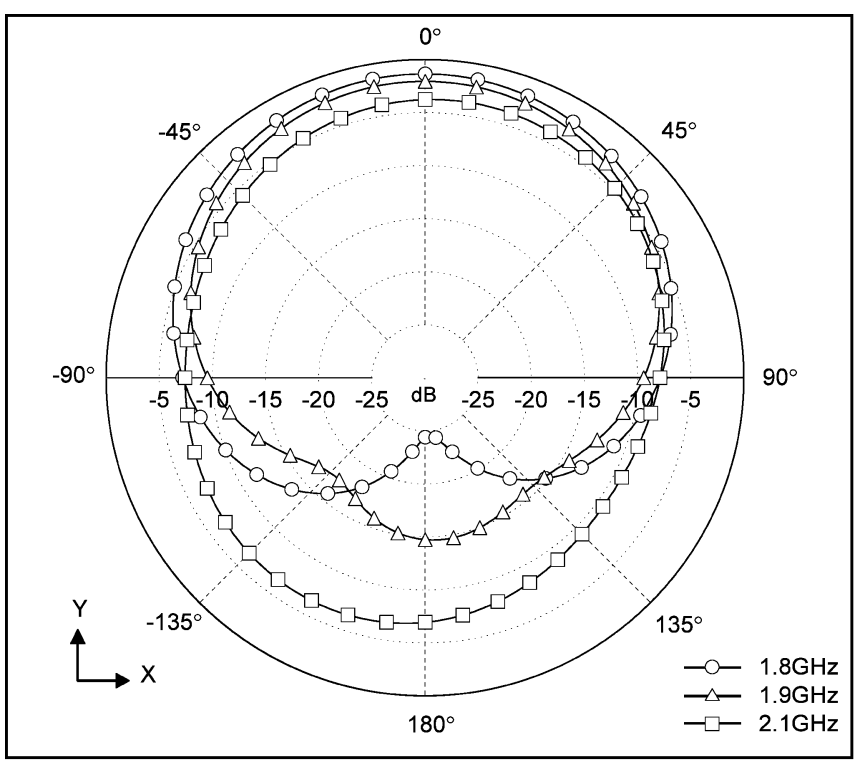

(a)

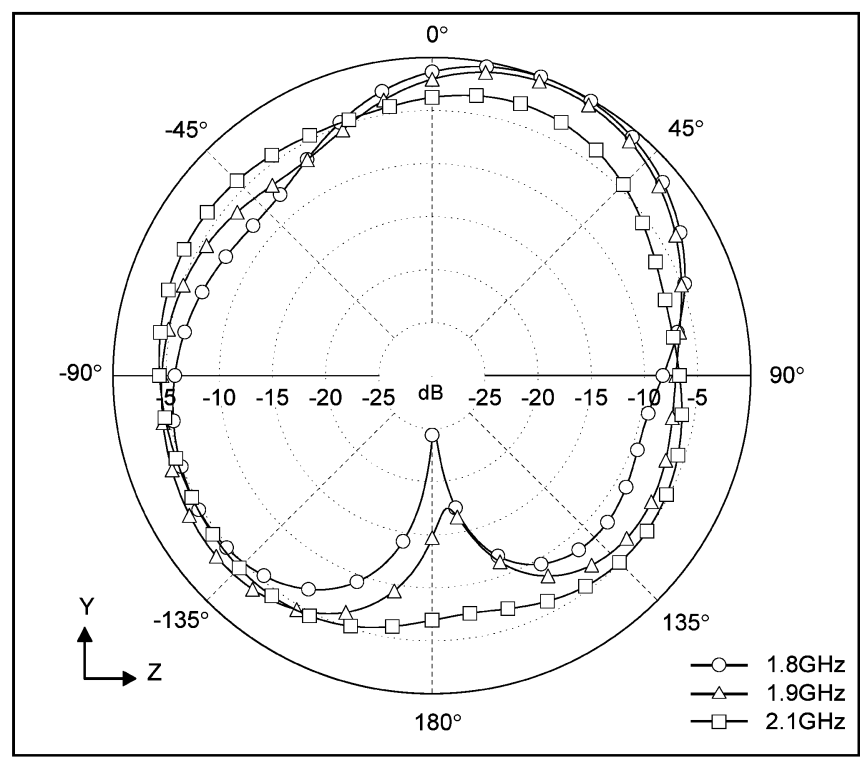

(b)

Fig. 11. Simulated radiation patterns of handset of Fig. 9. (a) yx plane without head and (b) yz plane without head.

successfully at $-6 \mathrm{~dB}$ are the GSM1800, 1900 and UMTS, as shown in Fig. 10.

The corresponding efficiencies are $21 \%, 16 \%$, and $12.5 \%$. Even though they are decreased compared to their quad-band counterparts presented earlier, they are very encouraging considering that this design uses material designed for screening purposes. The reduction of the material loss for antenna applications will require adjustment of the material composition and processing. Note that the Bluetooth band was well matched but the efficiency could not be increased above a few percent due to the position of the rings.

The pattern cuts are shown in Fig. 11 and as for the quad-band antenna they have smooth overall coverage whilst maintaining the pattern nulls necessary for low SAR operation.

\section{DISCUSSION AND CONCLUSION}

The advantages of coating a wire antenna with ferrite material, as opposed to dielectric material alone, have been demonstrated both theoretically and experimentally. It is established that apart from higher radiation efficiency and bandwidth, this material coating enables better control to be exerted over the antenna fields when placed close to the handset ground plane, and thus contributes to positioning an axial pattern null towards the head and having a very low SAR. This is unlike PIFA and meanderline antennas, which may have higher efficiencies in free-space but are greatly affected by their local environment and lead to reduced efficiencies and higher SAR values in the presence of the head.

Developmental simulation work translated the aforementioned attributes into a quad-band handset antenna design, which with a $\mu^{\prime} \sim 6.4$ combined excellent band performance with high efficiency and a very low SAR. A tri-band antenna design was also developed $\left(\mu^{\prime} \sim 2\right)$ to explore the antenna's potential with currently available ferrite material. Despite a drop in efficiency, the antenna behaved very satisfactorily both in terms of band coverage and SAR. It is concluded that the specific development of ferrite material that is more suitable for antenna applications, can lead to a commercially viable high efficiency and low SAR multiband handset antenna.

\section{ACKNOWLEDGMENT}

The authors acknowledge the contribution of Flomerics for the use of their MicroStripes TLM modelling tool.

\section{REFERENCES}

[1] R. W. P. King and G. S. Smith, Antennas in Matter. Cambridge, MA: The MIT Press, 1981.

[2] K. Fujimoto, A. Henderson, K. Hirasawa, and J. R. James, Small Antennas. Letchworth, U.K.: Research Studies Press, 1987, ch. 3, pp. 195-265.

[3] G. Bit-Babik, C. Di Nallo, and A. Faraone, "Multimode dielectric resonator antenna of very high permittivity," in Conf. Rec. 2004 IEEE Int. Conf. Antennas and Propag., pp. 1383-1386.

[4] Z. Wong, C. C. Chiau, X. Chen, B. S. Collins, S. P. Kingsley, S. C. Puccey, and J. R. Thorpe, "Study and optimisation of a broadband dielectric antenna," in Conf. IWAT'05, Singapore, Mar. 2005, pp. $125-128$.

[5] J. R. James and A. Henderson, "Electrically short monopole antennas with dielectric or ferrite coatings," Proc. Inst. Elect. Eng., vol. 125, no. 9, pp. 793-803, 1978.

[6] J. R. James and A. Henderson, "Investigation of electrically small VHF and HF cavity-type antennas," in Proc. Inst. Elect. Eng. Conf. on Antennas and Propagation, London, U.K., 1978, pp. 322-326.

[7] J. R. James and J. C. Vardaxoglou, "Investigation of properties of electrically small spherical antennas," Electron. Lett., vol. 38, no. 20, pp. 1160-1162, Sep. 2002.

[8] J. C. Vardaxoglou, J. R. James, and P. McEvoy, "Creating the definitive low SAR mobile antenna," in Institute of Physics Conf. on RF Interactions With Humans: Mechanisms, Exposure and Medical Applications, London, U.K., Feb. 27-28, 2003, (Abstract No ENV. 2.2, only).

[9] M. I. Kitra, P. McEvoy, J. C. Vardaxoglou, and J. R. James, "A theoretical and simulation study of dielectrically loaded antennas and their contribution towards low SAR," in Proc. ITG Conf. on Antennas (INICA), Sep. 2003, pp. 245-248. 
[10] J. R. James, R. Chair, K. M. Luk, K. M. Chow, K. W. Leung, and J. C. Vardaxoglou, "Influence of magnetic material on dielectric resonator antenna excitation," Proc. Inst. Elect. Eng. Microw. Antennas and Propag., vol. 151, no. 4, pp. 293-298, Aug. 2004.

[11] Wang and O. Fujwara, "Reduction of electromagnetic absorption in the human head for portable telephones by a ferrite sheet attachment," IEICE Trans. Commun., vol. E80-B, no. 12, pp. 1810-1815, 1997.

[12] K. Buell, H. Mosallaei, and K. Sarabandi, "Embedded circuit magnetic metamaterial substrate performance for patch antennas," in IEEE APS, 2004, pp. 1415-1418.

[13] C. A. Balanis, Advanced Engineering Electromagnetics. New York: Wiley, 1989, pp. 329-332, 519 .

[14] K. M. Luk and K. W. Leung, Dielectric Resonator Antennas. Baldock, U.K.: Research Studies Press, 2003, pp. 34-37.

[15] O. R. Cruzan, "Translational addition theorems for spherical vector wave functions," Quart. Appl. Maths, vol. 20, no. 1, pp. 33-40, 1962.

[16] H. A. Wheeler, "The radian sphere around a small antenna," Proc. IRE, no. 8, pp. 1325-1331, Aug. 1959

[17] G. S. Smith, "An analysis of the Wheeler method for measuring the radiation efficiency of antennas," IEEE Trans. Antennas Propag., vol. AP-25, pp. 552-556, Jul. 1977.

[18] K. Meier, V. Hombach, R. Kastle, R. Yew-Siow Tay, and N. Kuester, "The dependence of electromagnetic energy absorption upon human head modeling at $1800 \mathrm{MHz}$,' IEEE Trans. Mirow. Theory Tech., vol. 45, no. 11, pp. 2058-2062, Nov. 1997.

[19] S. Khalabatri, D. Sardari, A. A. Mirzaee, and H. A. Sadafi, "Calculating SAR in two models of the human head exposed to mobile phones radiation at 900 and $1800 \mathrm{MHz}$," in Progress in Electromagn. Research Symp., Mar. 2006, pp. 104-109.

[20] K. W. Kim and Y. Rahmat-Samii, "Antennas and human in personal communications: Applications of modern EM computational techniques," in Proc. 12th Int. Conf. on Microwaves and Radar, May 1998, vol. 4, pp. 36-55.

[21] A. Drossos, V. Santomaa, and N. Kuster, "The dependence of electromagnetic energy absorption upon human head tissue composition in the frequency range 300-3000 MHz," IEEE Trans. Microw. Theory Tech., vol. 48, no. 11, pp. 1988-1995, Nov. 2000

[22] K. Fujimoto and J. R. James, Mobile Antenna Systems Handbook, 2nd ed. Boston, MA, USA: Artech House, 2001, pp. 451-452.

[23] “DASY4 Dosimetric Assessment System Manual," Schmidt and Partner Engineering AG, 2003.

[24] K.-L. Wong, Planar Antennas for Wireless Communications. New York: Wiley, 2003.

[25] Z. Li and Y. Rahmat-Samii, "Optimisation of PIFA-IFA combination in handset antenna design," IEEE Trans. Antennas Propag., vol. 53, no. 5, pp. 1170-1778, May 2005.

[26] J. T. Rowley and R. B. Waterhouse, "Performance of shorted microstrip patch antennas for mobile communications handsets at $1800 \mathrm{MHz}$," IEEE Trans. Antennas Propag., vol. 47, no. 5, pp. 815-822, May 1999.

[27] G. R. Harrison, "Hexagonal ferrites for millimeter wave applications," in SPIE, 1981, vol. 317, Integrated optics and millimeter and microwave integrated circuits, pp. 251-261.

[28] H. Severin and P. J. Stoll, Z. Angew Phys., no. 3, pp. 209-212, 1967.

[29] H. L. Bertoni, Li-Hsiang, S. Cheo, and T. Tamir, "Frequency selective reflection and transmission by a periodic dielectric layer," IEEE Trans. Antennas Propag., vol. AP-37, pp. 78-83, Jan. 1989.

[30] S. Kingsley, Advances in Handset Antenna Design [Online]. Available: www.rfdesign.com May 2005, pp. 16-22

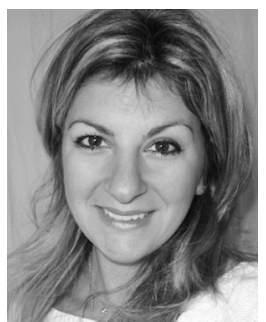

Maria I. Kitra (M'04) was born in Athens, Greece, in 1979. She received the B.Eng. degree in electronic and electrical engineering, the M.Sc. degree in digital communication systems and computer networks, and the $\mathrm{Ph} . \mathrm{D}$. degree in low-SAR material coated handset antennas from Loughborough University, Loughborough, U.K., in 2001, 2002, and 2006, respectively.

Her main research interests include the design of multiband mobile handset antennas and their user interaction. Following previous exposure to the field of metamaterials, she is currently investigating their ap-

plication in mobile handsets

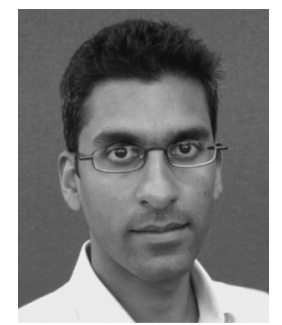

Chinthana J. Panagamuwa was born in London, U.K., in 1977. He received the M.Eng. degree in electronic and electrical engineering and the Ph.D. degree in optically controlled microwave switches and frequency reconfigurable antennas from Loughborough University, Loughborough, U.K., in 2000 and 2005, respectively.

$\mathrm{He}$ is currently a Research Associate at Loughborough University investigating the effects of facial jewelry on the SAR in the head. His main research interests are in optical control of silicon switches, frequency and beam reconfigurable antennas and low SAR handset antennas.

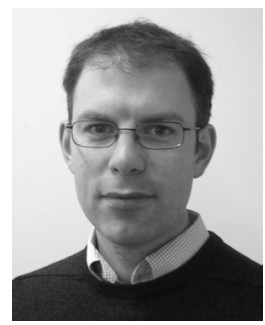

Patrick McEvoy (M'02) received the Technician Engineering Diploma in telecommunications and electronics from the Dublin Institute of Technology, Dublin, Ireland, in 1995 and the M.Eng. degree in electronic communications engineering from the University of Hull, Hull, U.K. (including a six-month secondment at L'Institut Supérieur d'Electronique de Paris, France) in 1998.

He joined the Centre for Mobile Communications Research, Loughborough University, U.K., in 1998 to research small dielectric loaded antennas for GPS and cellular telephony applications. He was promoted to Senior Research Engineer in 2001, Research Manager in 2004 and is currently working towards the Ph.D. degree. His research interests include small antennas, applications of metamaterials, low specific absorption rate antenna design, switched antennas for handheld terminals and antenna measurement systems. He has published 25 scientific papers and has participated in organizing three international conferences on antennas and propagation.

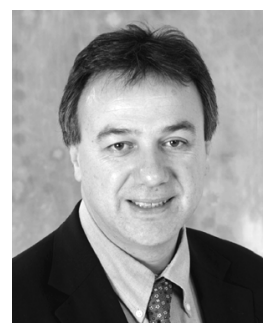

J. (Yiannis) C. Vardaxoglou (M'87) received the B.Sc. degree in mathematics (mathematical physics) and the Ph.D. degree from the University of Kent at Canterbury, U.K., in 1981 and 1985, respectively.

In January 1988, he was appointed a Lecturer in Communications with the Department of Electronic and Electrical Engineering, Loughborough University of Technology, Loughborough, U.K. He was promoted to the position of Senior Lecturer in January 1992. In 1998, he was appointed Professor of Wireless Communications. He holds the Chair of Wireless Communications at Loughborough University and is the Founder of the Centre for Mobile Communications Research (CMCR). He established the Wireless Communications Research (WiCR) group at Loughborough University and he Heads the Centre for Mobile Communications Research. He has pioneered research, design and development of frequency selective surfaces (FSS) for communication systems and has commercially exploited a number of his innovations. He has been active in the analysis and design of small low specific absorption rate (SAR) material loaded antennas for mobile telephony and electromagnetic band gap (EBG) structures for subsystem applications. His current research interests include array antennas, FSS, radomes, leaky wave resonant antennas, optical control of microwaves and devices, periodic surfaces and $\mathrm{EBG} / \mathrm{AMC} / \mathrm{LH}$ materials, and material-loaded mobile telephone antennas. He has served as a consultant to various industries, holds three patents and is the Technical Director of Antrum, Ltd. He has published over 130 refereed journals and conference proceeding papers and has written a book on FSS.

Dr Vardaxoglou is currently the Chairman of the executive committee of the IEE's Antennas and Propagation Professional Network in and he chairs the IEEE's Distinguish Lecturer Program of the Antennas and Propagation society. He Chairs the Executive Committee of Metamorphose, EU FP6 Network of Excellence of Metamaterials. He chaired the 1st and 2nd IEE Antenna Measurements and SAR (AMS'02 and AMS'04) conferences and has been in the organizing committee of the 2001 and 2003 IEE International Conferences on Antennas and Propagation. He was the general Chair of the 1st and 2nd Loughborough Antennas and Propagation Conference (LAPC'05). 


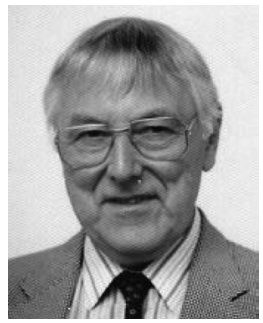

Jim R. James (deceased) was born in 1933 in Shanklin, on the Isle of Wight, U.K. He received the B.Sc. degree (special mathematics), in 1965, the Ph.D. degree in 1968, and the D.Sc. degree, in 1980, all from the University of London, London, U.K.

Following industrial experience in radar development, semiconductor manufacture and high-power accelerators, he joined the Royal Military College of Science, Shrivenham, U.K., as a Senior Lecturer in 1967. In 1976, he was appointed to a Research Chair in Electronics and was then appointed Professor of electromagnetic systems engineering in the School of Engineering and Applied Science. He specialized in defense-oriented research and directed the Wolfson RF Engineering Centre at the college. He published widely on research and development work in the fields of microwaves, antennas and speech processing, including papers in the Radio Engineer Institution Journal, for one of which he received the Heinrich Hertz Premium for 1973.

Dr. James was a member of the Papers Committee from 1970 to 1978 and its Chairman from 1972 to 1975; after completing a three-year period of service as an Ordinary Member of the Council he served as a Vice-President from 1975 to 1978 and again from 1979 to 2006. He was also a member of the Executive Committee. He served the profession as President of the Institution of Electronics and Radio Engineers in 1984 and was Chairman of the Institution of Electrical Engineers (IEE), London, U.K. Electronics Division in 1988. He was elected at the Royal Academy of Engineering in 1987. Following formal retirement he worked as an independent Consultant Engineer and was a Visiting Professor at Loughborough University. 